\title{
As mulheres na agenda da Organização Mundial de Comércio (OMC)
}

\author{
Women on the World Trade Organization (WTO) agenda
}

DOI: https://doi.org/10.22456/2178-8839. 113576

Silvana Schimanski

Universidade Federal de Pelotas, Pelotas, Brasil silvana.schimanski@ufpel.edu.br

\section{Resumo}

As mulheres foram incluídas, pela primeira vez, na agenda da OMC em dezembro de 2017, por meio da Declaração de Buenos Aires sobre Comércio e Empoderamento Econômico das Mulheres. A partir desse contexto, a pergunta que norteia este trabalho é: qual a contribuição da recente iniciativa da OMC para Economia Feminista? O objetivo geral é analisar a potencial contribuição da iniciativa à luz desse debate, também considerado recente na academia. Por meio da abordagem qualitativa, fontes primárias (documentos oficiais) e secundárias (bibliografia especializada e relatórios), com finalidade analítico-descritiva, o texto é dividido em três partes. A primeira contextualiza a temática, a segunda apresenta as principais organizações internacionais que têm desenvolvido o tema, a fim de que na terceira, seja possível caracterizar o trabalho da OMC. Conclui-se que, apesar da inserção tardia e por meio de uma iniciativa sem vínculo jurídico para os Membros da organização, o espaço permitirá aumentar a visibilidade da contribuição e dos desafios das mulheres no comércio mundial. Por seu potencial para inspirar discussões das políticas comerciais por meio do recorte de gênero, sem questionar suas bases androcêntricas, sua contribuição alinha-se ao eixo Economia de Gênero.

Palavras-chave: Organização Mundial do Comércio; Empoderamento econômico feminino; Feminismo;

\begin{abstract}
For the first time in the history of the WTO, women were included in the agenda in December 2017, through the Buenos Aires Declaration on Trade and Women's Economic Empowerment. From this context, the question that guides this paper is: what is the contribution of the recent WTO initiative for the Feminist Economy? The main objective is to analyze the potential contribution of the initiative in light of this debate, also considered recent in academia. Through the qualitative approach, primary (official documents) and secondary sources (specialized bibliography, reports), with analyticaldescriptive purpose, the text is divided into three parts. The first contextualizes the topic, the second presents most proemint international organizations addressing the topic, while the third, characterizes the work of the WTO. It is concluded that, despite the late insertion and through a non-binding initiative, it will increase the visibility of women's contribution and challenges to the world trade. Due to its potential to inspire trade policy discussion through gender lenses without, questioning androcentric basis, it contributes to the axis of Gender Economy.
\end{abstract}

Keywords: World Trade Organization; Women Economic Empowerment; Feminism; 


\section{Introdução}

Qual a contribuição da Declaração de Buenos Aires sobre Comércio e Empoderamento Econômico das Mulheres da OMC para a Economia Feminista? Este trabalho tem o objetivo de analisar a potencial contribuição da iniciativa, a partir das discussões desse debate, também considerado relativamente recente. A interface entre os estudos de gênero e a economia é um dos mais contemporâneos programas de pesquisa, que vem se consolidando a partir dos anos noventa, buscando dar visibilidade à contribuição das mulheres nesse campo. De uma maneira geral, defende que a introdução da categoria gênero aos debates, revela a insuficiência dos corpos teóricos tradicionais das ciências sociais para tratar adequadamente as desigualdades sociais entre mulheres e homens (NELSON, 1995;CARRASCO, 1999; FERNANDES, 2018).

$\mathrm{Na}$ dinâmica burocrático-institucional da Organização Mundial do Comércio (OMC), é recente o debate alusivo ao empoderamento econômico das mulheres. Mais recente ainda, é o espaço institucional que visa dar visibilidade às contribuições e desafios das mulheres, tanto relativos aos aspectos políticos, quanto à própria inserção nos fluxos do comércio mundial. Trata-se, portanto, de significativa conquista da décima primeira Conferência Ministerial, ocorrida em dezembro de 2017, em Buenos Aires (WTO, 2017a).

A inclusão da temática, porém,não resultou de uma Decisão Ministerial, instrumento que poderia possuir caráter vinculativo entre os atuais 164 Membros da Organização. Sua inclusão se deu por meio de um compromisso assumido entre 118 Membros e Observadores, os quais apoiaram um documento intitulado “Declaraçãode Buenos Aires sobre Mulherese Comércio”. O texto do referido documento, sugere que sejam explorados caminhos acerca dos principais desafios à participação das mulheres no contexto do comércio internacional (WTO, 2017b). Trata-se mais de um instrumento de intenções do que de resultados (pelo menos, até o momento).

Ainda assim, o debate em torno do empoderamento econômico das mulheres, passou a compor uma agenda própria entre os "novos temas"1 da OMC. Nessa agenda, os Membros se comprometem a avançar os diálogos e promover estudos sobre aspectos negligenciados ou desconhecidos, como diagnósticos. Ou seja, pela primeira vez, desde as suas origens na década de 1940 (nos tempos do Acordo Geral Sobre Tarifas e Comércio), a OMC busca dar visibilidade ao papel das mulheres na arena das políticas comerciais e dos fluxos de comércio mundial (TICKNER, 2001; PETERSON, 2003, 2005; TRUE, 2012; ENLOE, 2014).

Até o ano de 2017, a discussão sobre o papel das mulheres no comércio internacional foi timidamente presente na organização, basicamente, por meio de apresentações de experts nos Fóruns Públicos - cujos registros apontam trabalhos apresentados sobre a temática desde o ano de 2001 - e nas celebrações do dia internacional da mulher (WTO, 2021). Dado o avanço e aprofundamento das discussões em outras organizações internacionais governamentais (especialmente nas econômicas) e, até mesmo, em arranjos regionais de comércio (MONTEIRO, 2021), não foi mais possível blindar a OMC desse debate, já que o comércio possui um importante papel no empoderamento econômico das mulheres.

Sob a perspectiva de gênero, por meio da abordagem qualitativa, com fontes primárias (documentos oficiais) e secundárias (bibliografia especializada e relatórios) e com finalidade analítico-descritiva, o trabalho está dividido em três partes. A primeira contextualiza o debate, a segunda apresenta as diferentes organizações internacionais envolvidas com a temática, para que por fim, seja caracterizado o trabalho desenvolvido na OMC e sua dinâmica até o momento.

\section{Economia, gênero e empoderamento econômico}

Um relatório publicado recentemente apresentou a conclusão de que, na trajetória corrente, caso os países não adotem mudanças significativas em suas políticas, o mundo levará entre 99.5 a 135.6 anos para fechar as lacunas da desigualdade de gênero (WEF, 2021b). Como a ampliação desse debate tem ocupado diferentes espaços com diferentes

\footnotetext{
Juntamente com discussões sobre Pequenas e Médias Empresas e Comércio Eletrônico. Vale lembrar que muitos dos temas que hoje possuem acordos formais na OMC, passaram antes, por essa fase, como por exemplo, o tema facilitação de comércio, cujo Acordo de Facilitação de Comércio foi concluído em 2013.
} 
agendas, contextualizá-lo no campo da Economia é necessário para compreender seu ingresso na agenda da Organização Mundial do Comércio.

Tradicionalmente, a Economia foi um campo construído sobre premissas como neutralidade, racionalidade, objetividade, concepções matemáticas da filosofia cartesiana, defendidas como garantidoras da sua separação de campos considerados "mais suaves" das ciências sociais (como por exemplo, a sociologia) ${ }^{2}$. Ao teorizar sobre gênero e ciência, a corrente da Economia Feminista passa a argumentarque como qualquer outra ciência, a Economia tambémé socialmente construída. Uma vez que seus padrões são determinados a partir de experiências implícitas, as abord agens tradicionais refletem o ideal de masculinidade nos seus modelos, métodos, temas e pedagogia. Portanto, advogam a favor da adequação do escopo ferramental, que permita mais amplo entendimento das atividades econômicas, os quais favoreceriam avanços na disciplina e na sociedade (NELSON,1995).

A Economia Feminista é crítica das representações abstratas do mundo usadas pelas abordagens tradicionais, que omitem e excluem as mulheres e as atividades fundamentais realizadas por esse grupo (todos os bens e serviços não remunerados que são produzidos, realizados e consumidos nas famílias, e sua exclusão das contas nacionais, por exemplo). Por não conseguir analisar restrições e situações específicas das mulheres, revelam sua fraqueza e nesse ponto, questionase até que ponto a Economia é positiva e objetiva. O argumento é que os modelos e métodos são enviesados pela exclusividade dos tópicos associados ao masculino (bens, serviços, ativos financeiros remunerados pelo mercado), ocultando os temas associados ao feminino (cuidados da casa, das crianças, dos idosos, entre outros) (NELSON, 1995; FERNANDES, 2018; GRECCO; FURNO; TEIXEIRA, 2018). Carrasco (1999, p. 7) aponta que a economia "[...] desde suas origens está atravessada por um recorte androcêntrico que marginaliza, oculta e torna invisível a atividade das mulheres”.

Antes de se consolidar como campo teórico nas ciências sociais, o movimento feminista, passou por etapas conhecidas como ondas ${ }^{3}$, que permitiram diversos recortes, bem como a consolidação de suas premissas. Para além das preocupações sociais e políticas que deram impulso inicial aos movimentos, a academia se inspirou nos questionamentos sobre aspectos filosóficos, epistemológicos e metodológicos. No campo da Economia, por exemplo, sua consolidação se dá a partir da década de 1990 (NELSON, 1995; CARRASCO, 1999; FERNANDES, 2018). Nas Relações Internacionais, trabalhos sobre o feminismo só começaram a aparecer a partir do final da década de 1980 (ENLOE,1989). Tais enfoques representam a crítica ao mainstream das disciplinas.

O gênero ${ }^{4}$ passou a ser entendido como uma categoria-chave para a compreensão de como e por que, em diversas sociedades e conjunturas históricas, os indivíduos, grupos e instituições atribuem determinados significados àquilo que deva ser, propriamente, associado ao masculino e ao feminino (NELSON, 1995; FERNANDEZ, 2018). A inclusão da categoria gêneroé fruto da considerada insuficiência dos corpos teóricos das ciências sociais de oferecer um tratamento adequadoà desigualdade social entre mulheres e homens (CARRASCO,1999).

Nas Relações Internacionais, o desafio de tornar as mulheres visíveis também foi ganhando força. Tickner (2001) aponta que o problema pelo qual as mulheres permanecem invisíveis na Economia Política Internacional seria o nível de análise convencional da disciplina que prioriza o Estado como ator unitário ${ }^{5}$. Excluí-las de indicadores ${ }^{6}$, estatísticas, programas ou políticas específicas, não apenas representa uma forma de discriminação, como de exclusão da sua contribuição com e para as políticas globais (TICKNER, 2001; PETERSON, 2003;2005; TRUE, 2012; ENLOE, 2014).

\footnotetext{
${ }^{2}$ Julie Nelson (1995) explica que essa noção está fundamentada sobre a associação da rigidez da ortodoxia como valorosa, à força masculina, enquanto a suavidade seria inferior, associada à fraqueza feminina.

3 A primeira onda tem suas origens no séc. XIX e XX e foi marcada pela luta para inserção das mulheres na política e pelo sufrágio universal. A segunda onda, na década de 1960, expandiu a discussão para as desigualdades institucionais informais e formais, in troduzindo o debate na academia. A Terceira Onda defende a pluralidade de vozes no feminismo, com um protagonismo de feministas negras e pós-colonialistas (FERNANDEZ, 2018).

${ }^{4}$ De uma forma geral, a escola feminista faz uma distinção entre sexo e gênero. Sexo é o termo que explica as diferenças biológicas, enquanto gênero, refere-se aos papéis sociais, estereótipos ou padrões sociais culturalmente construídos.

5 Apenas no século XXI diversas perspectivas teóricas surgem como desafiantes desse pressuposto.

${ }^{6}$ Por exemplo, Balanço de Pagamentos, indicadores financeiros como a taxa de juros, indicadores de comércio internacional, índices de preços, são considerados limitados e "gender blind", quando não são desdobrados sob o recorte de gênero.
} 
De uma forma geral, a crítica feminista não foi direcionada à Ciência Econômica em si, mas à forma como a ciência é produzida. Acusou os seus métodos de uma falsa neutralidade, ancorada em padrões androcêntricos (NELSON, 1995; CARRASCO, 1999; GRECCO; FURNO; TEIXEIRA, 2018). Experiências negligenciadas historicamente pelos homens são, também, negligenciadas teoricamente (NELSON, 1995). Ao defender mais objetividade o papel da teoria feminista, no geral, e da Economia Feminista, em particular, provocaram mudanças nas formas de entender o mundo.

Embora se reconheça que não há uma visão singular nas propostas, o mínimo denominador comum que permite o tratamento da economia feminista como um todo estruturado é a introdução do gênero como categoria analítica, também na Economia. Em essência, os principais debates contemplam três eixos: (i) critica a divisão sexual do trabalho, dando um grande aporte à esfera doméstica; (ii) desafios das políticas econômicas e seus efeitos na vida das mulheres, percebendo como o viés de gênero perpassa as estruturas econômicas; (iii) propõe outra economia, que tenha como eixo central a vida das pessoas (FERNANDEZ, 2018).

Sob escopo da Economia Feminista, há duas linhas de pensamento: (i) aquele que argumenta que a igualdade pode ser conquistada pela inserção da mulher da esfera masculina (trabalho remunerado, mercado, por exemplo); (ii) aquele que defende a necessidade do espaço da esfera feminina em todos os locais (economia, sociedade, política) (ENGLAND, 1993). A partir dessas linhas, alternativas possíveis de sistematização surgem, em função do grau de questionamento dos paradigmas androcêntricos: Economia de Gênero, Economia Feminista de Conciliação e Economia Feminista de Ruptura (OROZCO, 2005).

A Economia de Gênero pode ser entendida como uma das mais conservadoras, uma vez que propõe a incorporação dos recortes de gênero aos paradigmas econômicos existentes mantendo as dicotomias (economia-não economia; trabalho-não-trabalho) ${ }^{7}$. Argumenta que as desigualdades podem ser eliminadas mediante a manutenção do sistema econômico na forma como se apresenta, por meio da promoção de igualdade de oportunidades para que mulheres ocupem equitativamente os espaços historicamente ocupados pelos homens (OROZCO, 2005, 2006). Trata-se de um discurso objetivo, o qual a autora chama de "feminismo domesticado", voltado à análise dos diferenciais de participação e da discriminação feminina nos espaços tradicionalmente econômicos, visando direitos e oportunidades iguais para homens e mulheres.

As Economias Feministas de Conciliação e de Ruptura, por sua vez, defendem mudanças substantivas na forma de entender o sistema econômico e seu funcionamento, por questionar as bases epistemológicas. A Economia Feminista de Conciliação defende a redefinição dos conceitos fundamentais da economia e trabalho, recuperando o conjunto de atividades femininas que permanecem invisibilizadas, conjugando-os com conceitos e marcos tradicionais. Já a Economia Feminista de Ruptura, por sua vez, assume uma agenda mais ampla, situando o centro da análise na sustentabilidade da vida em todas as concepções conceituais e metodológicas. (OROZCO, 2005, 2006).

As três correntes identificadas têm em comum as relações de gênero como objeto legítimo do pensamento econômico, questionando as diferenças entre homens e mulheres, sem naturalizá -las. O Quadro 1 apresenta um esquema que demonstra ograu de ruptura com o androcentrismo.

${ }^{7}$ A esfera doméstica, portanto, continua sendo um espaço não integrado às ferramentas de análise. 
Quadro 1: Sistematização de diferentes enfoques

\begin{tabular}{|c|c|c|}
\hline $\begin{array}{c}\text { Grau de } \\
\text { Ruptura com }\end{array}$ & Categoria & Características \\
\hline & $\begin{array}{l}\text { Economia } \\
\text { de Gênero }\end{array}$ & $\begin{array}{l}\text { - Busca a inclusão das mulheres como sujeito e objeto de estudo dos } \\
\text { discursos androcêntricos preexistentes sem questioná-los. } \\
\text { - De certo modo, pode ser considerada um subconjunto da economia } \\
\text { ortodoxa (se diferenciando por isso, significativamente das demais } \\
\text { categorias). } \\
\text { - Embora reconheça que o âmbito de estudo dos enfoques dos } \\
\text { mercados seja masculinizado, não o questiona, porém, enfatiza a } \\
\text { relevância de que as próprias mulheres analisem as experiências } \\
\text { femininas nos mercados. } \\
\text { - Propõe medidas de igualdadede oportunidadespara que as mulheres } \\
\text { entrem nos mercados. }\end{array}$ \\
\hline & $\begin{array}{l}\text { Economia } \\
\text { Feminista } \\
\text { de } \\
\text { Conciliação }\end{array}$ & $\begin{array}{l}\text { - Considera factível e conjugar os paradigmas androcêntricos } \\
\text { preexistentes com as modificações que requer a adoção de uma } \\
\text { perspectiva feminista (trabalhodoméstico, reprodução, etc). } \\
\text { - Propõe certas transformações com vistas a garantir a igualdade, } \\
\text { como políticas de conciliação do trabalho remunerado com o não } \\
\text { remuneradodoâmbitofamiliar. }\end{array}$ \\
\hline & $\begin{array}{l}\text { Economia } \\
\text { Feminista } \\
\text { de Ruptura }\end{array}$ & $\begin{array}{l}\text { - Propõe mudanças profundas, com o questionamento das bases dos } \\
\text { discursos androcêntricos, sua epistemologia, conceitos e métodos. } \\
\text { - o uso do conceito de sustentabilidade da vida como categoria } \\
\text { primária da análise. } \\
\text { - Argumenta que a melhora econômica de todas as mulheres, não } \\
\text { apenas de determinados grupos, sé será possível pela modificação da } \\
\text { lógica mercantil e androcêntrica que domina o sistema econômico. }\end{array}$ \\
\hline
\end{tabular}

Fonte: Elaborado pela autora, a partir de Orozco (2005).

A pergunta feita por Cynthia Enloe no final da década de oitenta - onde estão as mulheres? - a fim de identificar os espaços ocupados no cenário internacional permanece relevante. Em seu trabalho, a autora procurou demonstrar que a política global é impactada e, ao mesmo tempo, moldada por atividades diárias de homens e mulheres. Reconhecer que, em inúmeros casos, homens e mulheres serão impactados de formas diferentes pelas políticas requer ferramentas de análises sensíveis ao recorte de gênero.

As políticas macroeconômicas, por exemplo, são frequentemente pensadas como políticas neutras. No caso da política comercial, definida como “[...] uma política do governo que influencia diretamente a quantidade de bens e serviços que um país exporta ou importa” (MANKIW, 2013, p. 394) a economia feminista entende, que não apenas tem efeitos nos níveis de emprego, nos preços, na renda e no crescimento econômico, como tais efeitos são diferenciados para homens e mulheres, em razão das diferentes posições na economia (trabalho remunerado, trabalho doméstico). Porém, até o momento, pouca atenção foi dada à formulação dessas políticas sensíveis ao gênero (BERIK; RODGERS, 2008; FERNANDEZ, 2018).

Há estudos que buscam produzir não apenas análises de gênero das políticas macroeconômicas e do crescimento econômico, mas também desenvolver teoria e metodologia macroeconômica com recorte de gênero e, por meio dessas estruturas, desenvolver políticas alternativas. Reformular a abordagem da macroeconomia requer um repensar fundamental das prioridades das políticas, mas principalmente, dos processos através dos quais elas são definidas, assumindo como tarefa própria a proposta de soluções (OROSCO, 2005; BERIK; RODGERS, 2008).

Como um dos principais objetivos do movimento feminista é a promoção da capacidade de ação - considerando capacidades inexistentes ou diminuídas - na área econômica esse conceito foi amplamente difundido como empoderamento econômico. 
[...] a expansão da capacidade de ação neste caso representa o empoderamento feminino por intermédio da obtenção de um emprego, do desenvolvimento de uma carreira e de uma vida profissional e, como consequência, a obtenção da independência financeira. A expectativa dos vários enfoques da economia feminista é a de que esta possibilidade dependerá, por um lado, do tratamento teórico destas questões para que, por outro, possa se dar a eliminação política das causas que levaram a restrição da ação feminina, nomeadamente no campo laboral. Assim, expandir o exercício da ação torna -se um ponto fulcral tanto do movimento político do feminismo, quanto do projeto teórico da economia feminista (FERNANDES, 2018, p. 562).

Embora não haja ainda uma definição única acerca do que seja empoderamento econômico feminino, Golla et al. (2011) preferem dizer que trata-se do resultado de um processo, pelo qual as mulheres têm garantido o direitoigualitário ao acesso aos mercados e recursos financeiros, bem como, poder para tomar decisões e controlar seus recursos econômicos, a fim de exercer maior participação sobre diferentes áreas da vida. Para esse grupo de autoras "uma mulher é economicamente empoderada quando possui, tanto a habilidade para ter sucesso e avançar economicamente, quanto o poder de agir e tomar decisões econômicas” (GOLLA et al., 2011, p. 3, traduçãonossa).

Paralelamente ao debate acadêmico, o conceito de empoderamento econômico das mulheres avançou no âmbito das organizações internacionais e da agenda para o desenvolvimento. É crescente o reconhecimento de que empoderar economicamente as mulheres contribui para o alcance de diversos aspectos relacionados ao desenvolvimento dos direitos humanos, como por exemplo: redução da fome e da pobreza, melhora dos indicadores de saúde, educação, entre outros (GOLLA et al., 2011). Ademais, sugere-se que o empoderamento econômico das mulheres pode ser uma forma de reduzir riscos associados à violência de gênero, desde que combinadas com perspectivas socioculturais (BOLIS; HUGUES, 2015; ISAKOVIC, 2018; UNICRI, 2021). Tem sido estratégia fundamental para visibilidade às questões como a falta de acesso aos recursos produtivos, aos meios de exercer atividades empreendedoras, já que em nenhum lugar do mundo as mulheres têm os mesmos acessos do que os homens (TRUE, 2012).

O conceito de empoderamento remonta às origens do ativismo feminista e abordagens como as promovidas a partir dos anos sessenta, pelo grupo Mulheres no Desenvolvimento (Women in Development - WID) e Gênero e Desenvolvimento (Gender and Development - GAD), nos anos subsequentes. Foram movimentos em defesa de processos que permitissem às mulheres, consciência sobre a dinâmica de dominação, construindo capacidades para a transformação radical das estruturas econômicas, sociais e políticas (PETERSON, 2003; CALVÈS, 2009).

Foi gradual a institucionalização do conceito ao vocabulário das organizações internacionais governamentais ${ }^{8}$, que mudou sua acepção a partir do final dos anos noventa. Enquanto nas origens o conceito esteve relacionado à mobilização coletiva para a mudança de estruturas políticas e modelos de desenvolvimento (bottom-up), atualmente, tornou-se sinônimo de capacidade individual, realização e status, deslegitimando movimentos coletivos. Outra crítica refere-se à sua utilização para legitimar políticas e programas de desenvolvimento de cima para baixo (top down) (CALVÈS, 2009). A atual instrumentalização do conceito, portanto, tem sido classificada como empoderamentoliberal, aoinvés de empoderamentolibertador (SARDENBERG, 2008).

No amplo contexto das interconexões entre diferentes atores - tanto domésticos, quanto internacionais - há contribuições para o desenvolvimento e a difusão de práticas e políticas em prol da igualda de de gênero. Entre os atores domésticos podem ser mencionadas as instituições governamentais, sociedade civil e atores privados, como por exemplo, empresas, instituições financeiras, entre outros. Entre os atores internacionais, o papel das organizações internacionais merece destaque, por seu aspecto institucionalizado de promover a cooperação internacional, impulsionando algumas mudanças de padrões (ISAKOVIC, 2018; OLIVEIRA; SARAIVA; SAKAI,2020).

Apesar da instrumentalização do conceito de empoderamento econômico para um formato considerado distante do inicialmente proposto, autores defendem a sua reconexão com a acepção original, a qual envolve um complexo

\footnotetext{
8 A autora menciona que a Conferência Internacional para a População e Desenvolvimento, realizada no Cairo em 1999, foi uma das primeiras Conferências das Nações Unidas a dar visibilidade internacional ao conceito, em virtude da significativa participação de redes de ativistas femin istas no evento. (CALVÈs, 2009).
} 
processo que foca nas dimensões individuais e coletivas de poder (SARDENBERG, 2008; CALVÈS, 2009). O argumento é que o empoderamento foi domesticado e tirado dos trilhos originais. Na próxima seção, será possível mapear as principais organizações internacionais econômicas nas quais o conceito tem sido utilizado.

\section{Empoderamento econômico das mulheres nas Organizações Internacionais}

Com o intuito lançar luz aos desafios sobre o empoderamento econômico das mulheres, várias organizações internacionais desenvolvem iniciativas e estudos, por meio dos quais procuram compreender em que medida os Esta dos e suas estruturas, juntamente com as interações econômicas, repercutem de forma desigual na vida dos indivíduos. Entre os principais, estão os trabalhos da Organização das Nações Unidas (ONU), do Fundo Monetário Internacional (FMI), do Banco Mundial, da Organização para Cooperaçãoe Desenvolvimento Econômico (OCDE), do Fórum Econômico Mundial e o Centro Internacional de Comércio (ITC). ${ }^{9}$

As organizações internacionais, em especial as governamentais, são atores proeminentes, considerando os diversos mecanismos que possuem, capazes de influenciar mudanças em políticas domésticas ${ }^{10}$. Tais organizações, portanto, podem ser entendidas como agentes de transferência e difusão de políticas públicas, adotando desde instrumentos legais vinculantes ou mecanismos de condicionalidade, até estratégias mais brandas, como apoio a projetos ou agendas por afinidade, recomendação de modelos ou boas práticas, medidas de apoio e financiamento (OLIVEIRA; SARAIVA; SAKAI, 2020).

$\mathrm{Na} \mathrm{ONU}$, o empoderamento econômico das mulheres é fruto de debates da década de quarenta (na Comissão do Status da Mulher), que levaram à Convenção para a Eliminação de Todas as Formas de Discriminação contra a Mulher (de 1979), a qual possui caráter vinculativo nos países signatários (UN, 1979). O documento, manifesta o entendimento de que o empoderamento econômico das mulheres é essencial para aproximar a sociedade da igualdade de gênero, do crescimento econômico inclusivo e da erradicação da pobreza.

A partir desse entendimento, a organização tem atuado em diversas frentes, amparada por uma série de instrumentos e instituições, produzindo relatórios com recortes de gênero e planos de ação. A Plataforma para Ação, fruto da Declaração de Pequim, por exemplo, tem promovido uma agenda progressiva de políticas públicas para o avanço dos direitos das mulheres (UN, 1995).

Em 2015, estes trabalhos contaram com um importante reforço, com a aprovação dos dezessete Objetivos para o Desenvolvimento Sustentável (ODS) (UN, 2015). Entre eles, há metas para a conquista da igualdade de gênero e empoderamento econômico de todas as mulheres e meninas (ODS 5), para as quais os diversos atores sociais, além dos governos nacionais e subnacionais, também são chamados a contribuir, como os movimentos sociais e as emp resas.

Ao longo do tempo, os relatórios têm apresentado evidências de que os principais desafios enfrentados pelas mulheres persistem. Por exemplo, as mulheres ainda têm dificuldades para conciliar o trabalho remunerado, criar filhos(as) e o trabalho doméstico não pago; embora a incorporação das mulheres no mercado de trabalho continue crescendo, casamento e a maternidade reduzem as taxas de participação e, portanto, de renda e benefícios associados; globalmente, as mulheres ainda são menos remuneradas do que homens (recebendo aproximadamente $23 \%$ menos); mulheres têm menos acesso às instituições bancárias ou a contas bancárias; mulheres enfrentam mais dificuldades ao empreender no mundo dos negócios (UN WOMEN, 2018; UN WOMEN, 2019).

\footnotetext{
${ }^{9}$ Embora inúmeras outras organizações sejam relevantes para o debate, dadas as limitações do trabalho foca-se nestas a título de exemplo e, especialmente, por seu poder de difusão política.

${ }^{10}$ As organizações internacionais não governamentais, também são capazes de promover mudanças, embora lancem mão de outras estratégias - como por exemplo, colaboração ou confronto - com atores governamentais.
} 
No âmbito do Fundo Monetário Internacional (FMI), a ex-Diretora Geral Christine Lagarde ${ }^{11}$ afirma que os debates sobre empoderamento econômico feminino, iniciados na década de 1970, foram ofuscados com a crise do petróleo e a ênfase dada às questões macroeconômicas, como o fim do sistema das taxas de câmbio fixas. Na sua visão, o debate, agora, retorna com força, especialmente, em virtude do entendimento entre os economistas, acerca dos amplos benefícios sociais que advém do aumento da participação feminina na economia, entre os quais: crescimento do PIB, diversificação das economias, ampliação renda, entre outros (LAGARDE, 2017).

O FMI além de incorporar considerações relacionadas às políticas de gênero em suas recomendações aos países, também vem destacando o importante papel,tanto das políticas fiscais, quanto das políticas de apoio, como por exemplo, benefícios tributários, esquemas de apoio e benefícios aos pais trabalhadores, entre outros. Ademais, recomenda fortemente que o recorte de gênero esteja presente nas discussões orçamentárias dos países, bem como, que suas execuções sejam monitoradas de uma forma transparente. De uma forma geral, os estudos do FMI têm demonstrado ganhos macroeconômicos significativos, a partir da maior participação das mulheres nos mercados (LAGARDE, 2017; IMF, 2021).

O Banco Mundial pode ser considerado outro ator de destaque, especialmente, no quesito transferência e difusão de políticas públicas, uma vez que ao estabelecer empréstimos condicionados, direciona os países na busca de soluções para determinados problemas, por meio da difusão de boas práticas ${ }^{12}$. $\mathrm{Na}$ área de gênero, a instituição tem trabalhado nas últimas décadas, visando contribuir com políticas de redução das desigualdades, reconhecendo que os principais desafios sociais afetam meninos, meninas, homens e mulheres de formas diferentes, principalmente, em virtude de leis e políticas discriminatórias, mas também em virtude de normas sociais que influenciam os seus papeis e responsabilidades na sociedade (WORLD BANK, 2015; WORLD BANK, 2020).

Um dos estudos publicados, aponta que mais de 1500 reformas foram realizadas em 190 países, nos últimos 50 anos, para aprimorar a participação econômica das mulheres. Todavia, em termos de perspectivas como empreendedoras e trabalhadoras, as mulheres ainda têm somente três-quartos dos diretos legais. Muitos instrumentos jurídicos ainda desestimulam as mulheres de entrar no mercado de trabalho ou iniciar um negócio e tal discriminação tem efeitos duradouros (WORLD BANK, 2020).

Outro estudo do Banco Mundial, específico sobre o papel que o comércio pode desempenhar no empoderamento econômico das mulheres, evidencia a ausência de políticas com um enfoque de gênero. $\mathrm{O}$ estudo destaca que as novas tendências no comércio global - especialmente o aumento do setor de serviços, a economia digital e as cadeias produtivas globais - estão abrindo importantes oportunidades para as mulheres. Entretanto, para que sejam acessadas, muitos países precisam adotar reformas também em suas políticas comerciais e investir na formação do seu capital humano (THE WORLD BANK GROUP; WTO, 2020).

A OCDE é outra organização que tem direcionado seu trabalho, a partir do recorte de gênero para questões econômicas, focando, principalmente, no exame das barreiras existentes para o acess oigualitário à educação, emprego $\mathrm{e}$ empreendedorismo ${ }^{13}$ (OECD, 2021). Entre suas contribuições, merecem destaque os relatórios com recomendações de políticas públicas baseados nas boas práticas (OECD, 2013).

Segundo o documento, o papel governamental, de uma forma geral, seria articular legislação, políticas, campanhas informativas e de monitoramento, por meio dos quais os países pudessem adotar práticas de promoção de igualdade de gênero. Como exemplo, são citadas: estímulo à educação e carreira em diversa s áreas; promoção de políticas que estimulem pais a equilibrar responsabilidades profissionais e tarefas domésticas; aumento da participação das

\footnotetext{
${ }^{11}$ Christine Lagarde, atualmente é Presidente do Banco Central Europeu. Entre 2011-2019, foi Presidente e Diretora-Geral do FMI, tendo sido a primeira mulher a ocupar o posto, atualmente ocupado por Kristalina Georgieva.

12 O Umbrella Facilitiy for Gender Equality (UFGE), por exemplo, é um fundo de vários doadores do Grupo Banco Mundial, que financia pesquisas, avaliações de impacto e dados para ajudar os formuladores de políticas e profissionais a eliminar as lacunas de gênero em países e setores. A iniciativa financiou trabalhos em mais de 90 países, influenciando políticas e programas nessa área.

${ }^{13}$ A ferramenta SIGI-Centro de Instituições Sociais e Indicadores de Gênero, tem sido utilizada para reunir e divulgar medidas discriminatórias contra mulheres em instituições sociais (formais e informais), de 180 países.
} 
mulheres nas arenas decisórias; fortalecimento da diversidade de gênero e cargos de alta chefia nos setores público e privado; eliminação de práticas salariais discriminatórias; promoção da reconciliação entre vida profissional e familiar; promoção de medidas de prevenção a todos os tipos de assédio; redução da lacuna de gênero nas atividades empreendedoras e empresariais; redução das lacunas de acesso ao mercado financeiro (OECD, 2013).

Por sua vez, o documento reconhece que sozinhos, os Estados por meio da atuação governamental, frequentemente são incapazes de promover tais mudanças sociais. Portanto, recomenda a cooperação com relevantes atores, entre eles, setor privado, agências públicas, entidades comerciais, sindicatos e outras organizações da sociedade civil (OECD, 2013).

O fato é que o empoderamento econômico das mulheres, nas instituições citadas e em outras, tem sidoum tema revisitado, como uma tarefa pendente. Ganhou um novo fôlego no rastro das discussões sobre a agenda dos ODS, para que até 2030, o desenvolvimento sustentável seja alcançado, sem deixar ninguém para trás. O destaque à importância do comprometimento dos mais diversos atores sociais, em diversos níveis, com as metas propostas, ampliou, significativamente, o alcance de debate (UN, 2015).

É nesse contexto que até mesmo na agenda do Fórum Econômico Mundial ${ }^{14}$, o empoderamento econômico feminino ganhou destaque. Há diversas publicações que apontam que nenhum país do mundo ainda foi capaz de fechar as lacunas existentes entre homens e mulheres, de forma que ações e propostas têm sido discutidas, estimulandolideranças de empresas e países a pensarem estratégias para a superação de tais lacunas. Diversas publicações apontam que algumas situações continuam minando oportunidades das mulheres e por isso, têm defendido, entre outras ações, a ampliação da representatividade política, alteração de legislação e atitudes sociais e culturais, cuidados domésticos não remunerados e a participação das mulheres nos negócios (WEF, 2021).

O movimento das organizações econômicas deixava evidente o silêncio da OMC acerca da temática. Os levantamentos com recorte de gênero, realizados pelo Centro Internacional de Comércio ${ }^{15}$, foram fundamentais para aumentar a sensibilização sobre as barreiras que dificultam a inserção das mulheres no comércio internacional. Suas principais conclusões apontaram que apesar das mulheres administrarem aproximadamente 10 milhões de pequenos e médios negócios ao redor do mundo (justo aqueles responsáveis por aproximadamente $80 \%$ dos empregos), apenas uma em cada cinco insere-se no comércio internacional (ITC, 2015, 2016).

Os estudos também sugerem que são múltiplos fatores que levam à sub-representação dos negócios administrados por mulheres, no comércio internacional: barreiras culturais e regulatórias; pressão dos prazos envolvidos sobre as mulheres com filhos(as); a sobrecarga, uma vez que a maior parte do trabalho doméstico ainda recai sobre as mulheres (ITC, 2015). Iniciativas como acesso a serviços financeiros, informações sobre acesso a mercados e redes de fornecimento, capacitação e treinamento, maior transparência sobre questões re gulatórias e diminuição das barreiras não tarifárias sobre pequenas e médias empresas, são políticas que beneficiam a sociedade como um todo e, principalmente, aqueles negócios administrados por mulheres.

De uma forma geral, é possível observar que as organizações econômicas internacionais têm se envolvido no processo de organização e publicação de evidências empíricas sobre a situação das mulheres na economia. Por certo, análises mais profundas precisam ser realizadas, considerando a evolução de cada uma dessas agendas, bem como seus instrumentos de promoção de empoderamento econômico, a fim de investigar tanto em que medida propõem rupturas com androcentrismo proposto, quanto a instrumentalização conceito de empoderamento econômico. Por ora, a próxima seção foca em realizar esta análise para a agenda mais recente, da Organização Mundial do Comércio.

\footnotetext{
14 Organização sem fins lucrativos, que reúne lideranças empresariais e políticas, assim como intelectuais e representantes da mídia, para discutir as questões globais. É mais conhecido por suas reuniões anuais em Davos, na Suíça.

${ }^{15}$ O Centro Internacional de Negócios, foi criado em 1964, é uma organização de apoio da ONU e da OMC, para pesquisas e estratégias de implementação de políticas. Seu foco é fortalecer o setor empresarial, especialmente pequenas e médias empresas de países em desenvolvimento.
} 


\section{A inclusão do empoderamento econômico das mulheres na agenda da OMC}

$\mathrm{Na}$ estrutura da OMC, a inclusão formal de novos temas na agenda negociadora deve observar as regras previstas para processo decisório, ou seja, passar por etapas e consensos prévios, no âmbito do Conselho Geral, o qual encaminhará a proposta para aprovação ou não na Conferência Ministerial, instância decisória máxima ${ }^{16}$. Se aprovado, o tema figurará da Declaração Ministerial, vinculando os Membros da Organização para aquele mandato. Como uma organização governamental internacional que visa a liberalização comercial por meio de negociações multilaterais, uma das suas principais características é o seu processo negociador, o qual exige o consenso.

A inclusão da Declaração sobre o Empoderamento Econômico das Mulheres não seguiu este rito formal. Se deu por meio de uma iniciativa coletiva, que contou com a adesão voluntária dos Membros, em uma reunião lateral à Conferência Ministerial de Buenos Aires, realizada em dezembro de 2017 (WTO, 2017a). Na prática, significa que os compromissos do documento não vinculam juridicamente os signatários, os quais contribuirão por afinidade, para o alcance dos seus objetivos. Este fato já demonstra que a adoção de recortes de gênero no âmbito das políticas comerciais não alcança consensos dentro da referida organização.

Ainda assim, trata-se de uma conquista histórica já que desde o estabelecimento da OMC, foi a primeira vez que os Membros emitiram uma declaração em Conferência Ministerial, reconhecendo a importância de incorporar a perspectiva de gênero na promoção de políticas comerciais mais inclusivas (WTO, 2017a). Ou seja, por meio do apoio à Declaração de Buenos Aires, uma parcela significativa dos Membros reconheceu que a organização tem seu papel, para a promoção do empoderamento econômico das mulheres. Promover a introdução do gênero como categoria analítica das políticas comerciais e seus efeitos na vida das mulheres, percebendo como o viés de gênero perpassa as estruturas econômicas, marca a inclusão da OMC nos debates propostos pela economia feminista.

Um movimento interno já havia sido dado em junho de 2017, quando no Secretariado, foi nomeado um Grupo Focal para coordenar um recorte de gênero, nos trabalhos desenvolvidos nas diferentes divisões (WTO, 2021b). Entretanto, considerando a característica “member-driven” da organização a partir da qual, todas as iniciativas devem ser negociadas pelos Membros, a continuidade e aprofundamento dos trabalhos dependeria dos esforços políticos, que garantissem formalização e apoio.

As delegações da Islândia e Serra Leoa, bem como a Diretoria do Centro Internacional de Comércio, lideraram as reuniões com os Membros da OMC. Este direcionamento foi resultado dos esforços realizados pela rede Campeões Internacionais de Gênero ${ }^{17}$, a qual reúne lideranças - chefes de delegações, líderes de organizações internacionais governamentais e não governamentais - que apoiam o fim das barreiras de gênero. Aolongo de um ano, o grupo trabalhou em versões preliminares do documento, defendendo e compondo os argumentos que favoreceram o apoio por parcela significativa dos Membros (GENDER CHAMPIONS, 2021). A pressão pela busca de apoio ao documentojá sugere que seu conteúdo não poderia propor um viés considerado radical e deveria caminhar por terrenos mais conservadores, a partir daquilo que a diplomacia econômica já conhece. A Declaração de Buenos Aires, recebeu o apoio de 118 Membros e Observadores da $\mathrm{OMC}^{18}$, no contexto da sua décima primeira Conferência Ministerial. Seu texto, além de reconhecer a

\footnotetext{
${ }^{16} \mathrm{O}$ Acordo de Marraqueche, que estabelece a OMC prevê tal processo em seus Artigos IV (estrutura da OMC) e Artigo IX (processo decisório).

${ }^{17} \mathrm{O}$ “International Gender Champions-IGC" é uma rede que reúne tomadores de decisão femininos e masculinos, determinados a quebrar as barreiras de gênero e fazer da igualdade de gênero uma realidade de trabalho em suas esferas de influência.

${ }^{18}$ Afeganistão, Albânia, Argentina, Austrália, Áustria, Barbados, Bélgica, Benin, Brasil, Bulgária, Burundi, Camboja, Canadá, Chade, Chile, China, Colômbia, Costa Rica, Costa do Marfim, Croácia, Chipre, República Checa, República Democrática do Congo, Dinamarca, Dominica, Republica Dominicana, Equador, El Salvador, Estônia, Etiópia, Fiji, Finlândia, França, Gabão, Gambia, Alemanha, Grécia, Granada, Guatemala, Guiné, Guiné Bissau, Guiana, Haiti, Honduras, Hungria, Islândia, Indonésia, Irlanda, Israel, Itália, Jamaica, Japão, Cazaquistão, Kenya, Q uirguistão, República Democrática Laos, Letônia, Lesoto, Libéria, Liechtenstein, Lituânia, Luxemburgo, Madagascar, Malawi, Malásia, Mali, Malta, Maurício, México, Moldova, Mongólia, Montenegro, Myanmar, Namíbia, Países Baixos, Nova Zelândia, Niger, Nigéria, Noruega, Paquistão, Panamá, Paraguai, Peru, Filipinas, Polônia, Portugal, República da Coreia, Romênia, Federação Russa, Ruanda, Saint Kitts e Nevis, São Vicente e Granadinas, Samoa, Senegal, Serra Leoa, Eslováquia, Eslovênia, Somália, Espanha, Sudão do Sul, Suazilândia, Suécia, Suíça, Taipei, Tajiquistão, a antiga República Iugoslava da Macedônia, Togo, Tonga, Tunísia, Turquia, Uganda, Ucrânia, Reino Unido, Uruguai, Vanuatu, Vietnam, Zâmbia (WTO, 2017). Até abril de 2021, 127 Membros manifestaram suporte: a União Europeia (em bloco) além dos seguintes Membros: Andorra, Angola, Bahamas, Belarus, Botswana, Essuatíni, Georgia, Maldivas, Macedônia do Norte, Sérvia, Trinidad e Tobago, Emirados Árabes Unidos (WTO, 2021)
} 
necessidade de dar transparência às políticas de promoção do empoderamento econômico das mulheres e remoção de barreiras, com vistas a tornar o comércio internacional mais inclusivo, destaca a necessidade de evidenciar políticas que limitam a inserção das mulheres na economia (WTO, 2017b). Nesse sentido, foram propostas cincolinhas de ação:

1. Compartilhamento de experiências de cada membro, relativas a políticas e programas que encorajam a participação das mulheres na economia, através dos trabalhos dentro da própria OMC e voluntariamente, incluindo a temática nos relatórios de revisão de política comercial.

2. Compartilhamento de boas práticas de análises de políticas comerciais, com recorte de gênero, para monitoramento dos seus efeitos.

3. Compartilhamento de métodos e procedimentos para a coleta de dados, com recorte de gênero.

4. Trabalho conjunto na remoção de barreiras ao empoderamento econômico das mulheres, visando aumentar sua participação no comércio; e

5. Garantir que os fundos de ajuda financeira para o comércio apoiem os Membros quebusquem adotar ferramentas e instrumentos que permitam a análise, desenho e implementação de políticas comerciais com recorte de gênero.

Além das linhas de ação, a Declaração estabeleceu que nos meses posteriores (entre 2018 -2019) seriam realizadas ações coordenadas com outras organizações internacionais para explorar e discutir os temas relacionados ao papel do comércio no empoderamento econômico das mulheres, como por exemplo: a promoção do empreendedorismo e comércio; barreiras à participação das mulheres ao comércio; inclusão de negócios liderados por mulheres - especialmente pequenos e médios - em cadeias produtivas; entre outras (WTO, 2017b;2021).

Convém ressaltar o aspecto inovador naquele foro sobre as ações relacionadas ao empreendedorismoe negócios, visando reforçar as capacidades produtivas das mulheres. Tradicionalmente, a discussão sobre políticas comerciais e as políticas de empoderamento costumavam correr por trilhos paralelos, com poucos ou nenhum ponto de intersecção. Esta estratégia pode ser de grande utilidade para formuladores de políticas comerciais, uma vez que permitem ampliar o alcance do debate sobre gênero (FROHMANN, 2019).

Durante o período, uma série de eventos foram realizados, assim como a publicação de relatórios, promovendo a troca de experiências acerca de boas práticas. Também houve a intensificação da divulgação das oportunidades de apoio técnico e financeiro a projetos relacionados ao empoderamento econômico das mulheres. Por exemplo, o plano de capacitação da OMC para agentes governamentais, agora inclui um módulo sobre comércio e gênero; está prevista a criação de um programa de capacitação para mulheres empreendedoras; na iniciativa “Ajuda para o Comércio”, doadores favorecem a destinação de recursos financeiros a iniciativas que tenham impactos positivos no empoderamento econômico das mulheres (WTO, 2021).

Estas são estratégias características de difusão política, que permitem tanto o aprendizado, quanto estímulo externo à adoção de novas medidas, especialmente aquelas advindas de instrumentos nãovinculantes. Ou seja, a difusão ocorre, da esfera internacional para a doméstica dos países, na medida em que há fatores capazes de promover a interrelação entre os dois níveis (OLIVEIRA; SARAIVA; SAKAI, 2020). Pela ótica negociadora, também pode ser entendida como uma abordagem integrativa, a qual tem por objetivo quebrar possíveis resistências das partes, para negociações futuras (LEWICKI; SAUNDERS; BARRY, 2014).

Uma interessante demonstração do engajamento de alguns Membros com os dispositivos da Declaração de Buenos Aires já pode ser observada. União Europeia, Islândia e Gâmbia, por exemplo, já incluíram em seus Relatórios de Revisão de Política Comercial, capítulos nos quais destacam suas políticas que contribuem para a igualdade de gênero (WTO, 2021). A União Europeia, por exemplo, reforça seu engajamento com uma agenda ambiciosa do que o bloco reconhece como igualdade de gênero e empoderamento econômico das mulheres. Em capítulo específico, considera que as políticas comerciais contribuem para sua agenda por meio de ações específicas e horizont ais, destacando o aumento do 
seu foco nas ações de participação das mulheres em pequenas e medias empresas e em negócios digitais. A Islândia destaca a igualdade da participação de homens e mulheres no mercado de trabalho, bem como, esforços relacionados a o combate das diferenças salariais. Já no relatório da Gâmbia, ao longo do texto há divulgação de programas criados para a inclusão das mulheres no mercado, como por exemplo, no setor de pesca.

Este tipo de iniciativa lança luz sobre o papel do recorte de gênero, no desenvolvimento de políticas comerciais. Os exemplos acima demonstrados alinham-se aos argumentos propostos pela corrente liberal da economia feminista, de que a igualdade pode ser conquistada pela inserção da mulher da esfera masculina (trabalho remunerado, mercado, por exemplo). Em nenhum dos documentos citados há qualquer menção acerca da contribuição do trabalho doméstico ou não remunerado para o comércio internacional do país, por exemplo.

Entre 2014 e 2018 (antes da Declaração de Buenos Aires), 77 países de um total de 111 que se submeteram ao mecanismo de Revisão de Política Comercial, informaram medidas para o empoderamento das mulheres como parte das suas estratégias nacionais ou regionais. Estas incluem: compras governamentais, agricultura e pesca, incentivos financeiros e não financeiros ao setor privado e às pequenas empresas lideradas por mulheres. Alguns casos, inclusive, evidenciam o peso da presença das mulheres em determinados setores exportadores representativos, como é o caso da Colômbia, onde as mulheres representam 64\% da força de trabalho no ramo da floricultura (BOGHOSSIAN, 2019).

Políticas comerciais podem afetar as mulheres em todos os seus papéis econômicos. Como trabalhadoras e produtoras de bens e serviços, por exemplo, mulheres são afetadas por barreiras comerciais (tarifárias ou não tarifárias) impostas no destino, assim como pelas chamadas barreiras invisíveis (relacionadas a mecanismos de facilitação de comércio, infraestrutura, acesso a financiamentos para produção, para exportação, importação, etc). Como consumidoras, as mulheres também são afetadas pelas políticas que impactam os preços de bens e serviços (THE WORLD BANK GROUP; WTO, 2020). Considerando que os empregos das mulheres tendem a ser concentrados em setores que sofrem mais restrições, menor acesso aos mercados externos e mais sensíveis às variações de preços, há escopo para discussões no âmbitoda OMC.

Há casos, como de países como Canadá, Chile e Uruguai, por exemplo, que recentemente têm incluído capítulo de gênero em seus acordos comerciais. Embora tais capítulos não tenham muita ênfase sobre aspectos técnicos, buscam compartilhar princípios e mecanismos de cooperação a fim de que sejam alcançados maiores patamares de igualdade gênero (FROHMANN, 2019). Há um aumento significativo da inclusão de cláusulas de gênero em outros acordos comerciais e o dispositivo mais comum presente em tais arranjos regionais, é a promoção de cooperação para temáticas específicas dentro dessa agenda, considerando as mulheres no mercado, no trabalho remunerado (MONTEIRO, 2021).

Em setembro de 2020, outro importante passo foi dado na OMC, a partir da aprovação pela criação do Grupo Informal de Trabalho, por meio do documento (WT/L/1095/Rev.1) (WTO, 2020). Os trabalhos do grupo são abertos a todos os Membros e visam intensificar as atividades, até a próxima Conferência Ministerial marcada para ocorrer em novembro de 2021, em Genebra. As reuniões têm contado com a participação daqueles que apoiam iniciativas como a apresentada por Canadá (INF/TGE/W/1/Rev.2), de manter um cronograma de trabalhos, especialmente, para considerar o conceito de empoderamento econômico das mulheres e seu alinhamento com os trabalhos da OMC (WTO, 2021b). Sendo o objetivo da OMC a promoção da liberalização comercial, o debate de gênero ali tem assumido um caráter funcional, para a promoção da inclusão das mulheres ao mercado.

Se as mulheres chegaram para ficar na agenda de trabalhos da organização ainda é cedo para afirmar. Vale acompanhar como o tema será considerado pelos Membros, até a próxima Conferência Ministerial, a qual, inclusive, será a primeira presidida por uma mulher no cargo de Diretora Geral, Ngozi Okonjo-Iweala, nigeriana, recém-eleita e empossada em março de 2021

Em 2011, em discurso por ocasião da celebração do Dia Internacional da Mulher, o então Diretor Geral da OMC, Pascal Lamy, já reconhecia que embora o comércio internacional não fosse suficiente para enfrentar todas as injustiças 
sofridas pelas mulheres, era inegável admitir o seu papel. E que, portanto, os países deveriam garantir que as mulheres empresárias tivessem acesso a todas as oportunidades (WTO, 2011).

Em 2017, por ocasião da assinatura da Declaração de Buenos Aires, o Diretor Geral Roberto Azevêdo afirmou que o documento representava um importante passo para a promoção do empoderamento econômico das mulheres e construção de um sistema de comércio mais inclusivo (WTO, 2017a). Em 2021, primeira Diretor Geral da OMC, deixou seu recado: "Para meninas e mulheres que possam estar interessadas em uma carreira no comércio, [...] lembrem -se que o comércio nãoé um fim em simesmo: é um meio para o desenvolvimento” (WTO, 2021c,n.p., tradução nossa). De um modo geral é possível perceber que as discussões sobre gênero da OMC estão mais alinhadas à vertente conservadora e instrumental dos debates da esfera econômica.

\section{Considerações finais}

Este artigo buscou lançar luz sobre a tardia inclusão do debate sobre empoderamento econômico feminino, no contexto institucional da OMC. Como o tema ainda não foi discutido formalmente nas esferas negociadoras e com poder decisório (Conselho Geral e Conferência Ministerial), em 2017 a Declaração de Buenos Aires contou com a adesão voluntária de 118 Membros - atualmente, são127 - entre os seus 164 Membros. Ainda que seja por meio de um instrumento não vinculante e de alcance limitado, tem por objetivo promover a reflexão e trocas de experiências sobre como as atividades da organização podem contribuir com políticas que visam o empoderamento econômico das mulheres.

Entre 2018 e 2019 diversas atividades de aprendizado e trocas de experiências foram realizadas, todas demonstrando a importância de políticas que garantam o acesso às oportunidades de inserção no mercado, para essa significativa parcela populacional. Em 2020 aprovou -se a o estabelecimento de um Grupo Informal de trabalhos, visando dar continuidade aos estudos e discussões sobre políticas de empoderamento econômico das mulheres. A continuidade dos trabalhos, bem como, eventuais resultados e desdobramentos, dependerá do engajamento e da aprovação dos Membros da Organização, já que essa é a sua principal característica.

Em resposta à pergunta proposta, sobre qual a contribuição iniciativa sobre Comércio e Empoderamento Econômico das Mulheres da OMC para Economia Feminista, quatro pontos merecem destaque.

O primeiro ponto refere-se ao reconhecimento dos Membros da OMC, sobre a necessidade de recortes de gênero nas discussões sobre política comercial, uma das políticas macroeconômicas, entendidas como neutras pelos recortes tradicionais. Se a inclusão da categoria gênero nos debates econômicos é fruto da insuficiência dos seus corpos teóricos em oferecerem tratamento adequado às desigualdades entre homens e mulheres, há potencial para mudanças a partir dessa iniciativa. Todavia, tais mudanças dependerão de outros processos, especialmente no âmbito doméstico dos Esta dos, por meio da adoção de modelos, métodos ou mesmo tópicos que incluam aspectos hoje negligenciados (como trabalhos reprodutivos, trabalho doméstico, atividades não mercantilizadas), mas que os debates na OMC não abordam no momento.

O segundo aspecto é sobre o conteúdo da iniciativa: ao reconhecer que as políticas comerciais geram efeitos diversos para homens e mulheres, sugere como solução um debate sobre empoderamento econômico que está relacionado ao aumento das oportunidades para a inclusão das mulheres ao mercado. Nesse sentido, a iniciativa além de não romper com os padrões androcêntricos dos modelos existentes, mantém a divisão entre trabalho remunerado $\mathrm{x}$ trabalho doméstico. Alinha-se, portanto, ao feminismo domesticado do eixo Economia de Gênero, que propõe a incorporação dos recortes de gênero aos paradigmas econômicos existentes, mantendo as dicotomias. Considerando os próprios desafios impostos pelo contexto negociador da OMC, é possível inferir que propostas com viés da Economia Feminista de Conciliação ou de Ruptura, possivelmente encontrariam mais resistências e menos apoio para o início dos debates multilaterais naqueleforo. 
O terceiro ponto está relacionado ao conceito de empoderamento econômico adotado no âmbito da iniciativa proposta pela OMC. Ao utilizar-se do conceito instrumental já conhecido de outras organizações econômicas internacionais, considera que o empoderamento econômico feminino ocorrerá por intermédio da obtenção de um emprego, do desenvolvimento de uma carreira e de uma vida profissional e, como consequência, a obtenção da independência financeira. Como uma organização internacional focada na liberalização do comércio internacional, seu foco recai no mercado e não nas atividades tradicionalmente reconhecidas como fora do mercado.

Por fim, considera-se que a inclusão da temática no âmbito da OMC, embora no momento não possua um viés rupturista, nem proponha reinvenção de ferramentas analíticas, tem sua contribuição para a Economia Feminista também do ponto de vista empírico. O caso da OMC demonstra que os debates teóricos, metodológicos têm alcançado o âmbito político de alguma forma. Um desdobramento sempre desejável no âmbito da OMC é o de que as lideranças estatais se inspirem nos debates ali travados (mesmo antes da própria vinculação a instrumentos jurídicos internacionais) e promovam mudanças em suas políticas. Os resultados que ora demonstramos sugerem que o debate é ainda bastante objetivo e conservador em termos de propostas e soluções, porém, a depender das propostas d os próprios Membros, tem potencial para avanços.

Considerando que o debate na OMC é relativamente novo, este artigo não pretende esgotá -lo. Ao contrário: pretende instigar novas pesquisas, pois muitas perguntas ainda precisam ser feitas, como por exemplo: sendo o comércio uma das inúmeras atividades pelas quais as mulheres se inserem na economia, por que a Organização Mundial do Comércio demorou tanto a discutir sua parcela de contribuição? Os membros que não apoiaram a iniciativa, como aparecem e aparecerão nos indicadores relacionados ao empoderamento econômico das mulheres? Aderirão às discussões do Grupo Informal? Em que medida a iniciativa será capaz de criar mecanismos de difusão de políticas que façam, realmente, a diferença na vida de meninas e mulheres? As discussões do Grupo Informal avançarão para propostas negociadoras, no âmbito do Conselho Geral? Teriam as mulheres aberto a caixa de pandora, pavimentando o caminho para ampliação de novos recortes nas discussões sobre política comercial, como por exemplo, para agenda Queer ou outros grupos? Em que medida seria possível considerar os bens e serviços não remunerados nas contas comerciais?

A chegada da temática na OMC permite estimular os seus Membros a trocarem experiências, dialogarem e criarem políticas domésticas direcionadas para as mulheres, dando visibilidade à sua contribuição, bem como aos desafios particulares que enfrentam. Acima de tudo, cria oportunidades para que os tomadores de decisão discutam e adotem políticas inovadoras, considerando o recorte de gênero. Levar o feminismo a sério, não é simplesmente reconhecer a histórica invisibilidade das mulheres, mas, principalmente, fornecer contribuições a partir de todas as esferas de atuação.

\section{Referências}

BERIK, Günseli; RODGERS, Yana Van der Meulen. Engendering Development Strategies and Macroeconomic Policies: What's Sound and Sensible? In: BERIK, Gunselli; RODGERS, Yana Van der Meulen; ZAMMIT, Ann (Ed). Social Justice and Gender Equality Rethinking Development Strategies and Macroeconomic Policies. 1. ed. Oxfordshire: Routledge, 2008. cap. 1, p.1-44.

BOGHOSSIAN, Anoush der. Trade Policies Supporting Women's Economic empowerment: Trends in WTO Members. Staff Working Paper ERSD-2019-07. Geneva: World Trade Organization, 2019. Disponível em: https://www.wto.org/english/res_e/reser_e/ersd201907_e.pdf. Acesso em: 20 de março de 2021.

BOLIS, Mara; HUGHES, Christine. Women`s Economic Empowerment and Domestic Violence links and Lessons for Practicioners Working with Intersectional Approaches. Guatemala: Oxfam, 2015. Disponível em: https://s3.amazonaws.com/oxfamus/www/static/media/files/Womens_Empowerment_and_Domestic_Violence_-_Boris__Hughes_hX7LscW.pdf. Acesso em: 20 de abril de 2021.

CALVÈS, Anne-Emmanuèle.Empowerment:The History of a Key Concept in Contemporary Development Discourse. Revue Tiers Monde. Paris, v. 200, n. 4, p. 735-749, 2009. Disponível em: https://www.cairn-int.info/journal-revue-tiers-monde-2009-4-page735.htmto. Acesso em: 08 de julho de 2021.

CARRASCO, Cristina. Para uma economia feminista. 1999. Disponível em: https://www.sof.org.br/para-uma-economia-feministaintroducao/. Acesso em: 09 de julho de 2021. 
ENGLAND, Paula. The separative self: androcentric bias in Neoclassical Assumptions. In: FERBER, Marianne A.; NELSON, Julie (E ds.) Beyond Economic Man: Feminist Theory and Economics. Chicago: The University of Chicago Press, 1993. cap. 2, p.37-53.

ENLOE, Cynthia. Bananas, Beaches and Bases: Making feminist Sense of International Politics. $2^{\mathrm{a}}$ ed. Los Angeles: University of California Press, 2014.

Fernandez, Brena Paula Magno. Economia feminista: metodologias, problemas de pesquisa e propostas teóricas em prol da igualdade de gêneros. Revista de Economia Política. São Paulo v. 38, n. 3, p. 559-583, 2018. Disponível em: https://www.scielo.br/j/rep/a/hK9fwgQzytLqMh77BL7JBPF/abstract/?lang=pt. Acesso em: 09 de julho de 2021.

FROHMANN, Alicia. Herramientas de Política Comercial para Contribuir a la Igualdad de Género. Santiago: Comisión Económica para América Latina y el Caribe CEPAL. 2019.20 Disponível https://www.cepal.org/sites/default/files/publication/files/45063/S1901159_es.pdf. Acesso em:20 de abril de 2021.

GRECCO, Fabiana Sanches; FURNO, Juliane da Costa; TEIXEIRA, Marilane Oliveira. Por uma ciência econômica feminista. Temáticas, Campinas, v. 26, n.52, p.11-22, 2018. Disponível em: https://www.ifch.unicamp.br/publicacoes/pub/livros/2162. Acesso em: 08 de julho de 2021.

GENDER CHAMPIONS. Trade Impact Working Group. Geneva:2021. Disponível em: https:/genderchampions.com/impact/trade. Acesso em: 20 de março de 2021.

GOLLA, Anne Marie et al.; Understanding and Measuring Women's Economic Empowerment: Definition, Framework and Indicators. S.i: International Center For Research On Women (ICRW), 2011. Disponível em: https://www.icrw.org/wpcontent/uploads/2016/10/Understanding-measuring-womens-economic-empowerment.pdf. Acesso em: 20 de março de 2021.

INTERNATIONAL MONETARY FUND - IMF. Gender and the IMF. 2021. Disponível em: https://www.imf.org/external/themes/gender/. Acesso em:10 de março de 2021.

INTERNATIONAL TRADE CENTRE - ITC. Unlocking Markets for women to Trade. Geneva: ITC, 2015. Disponível em: https://www.intracen.org/uploadedFiles/intracenorg/Content/Publications/women_in_trade_web.pdf. Acesso em: 10 de março de 2021.

INTERNATIONAL TRADE CENTRE - ITC. Gender and Trade. Issue Brief Series. Geneva: ITC, 2016. Disponível em: https://www.un.org/esa/ffd/wp-content/uploads/2016/01/Gender-and-trade_ITC_IATF-Issue-brief.pdf. Acesso em: 01 de abril de 2021.

ISAKOVIC, Nela Porobic. A User Guide to Feminist Political Economy. $2^{\text {a }}$ Ed. S.i: Women's International League for Peace and Freedom - WILPF, 2018. Disponível em: https://www.wilpf.org/wp-content/uploads/2019/07/WILPF_Feminist-Political-EconomyGuide.pdf. Acesso em: 08 de abril de 2021.

LAGARDE, Christine. Every Woman Counts: Gender Budgeting in G7 Countries. 2017. Disponível em: https://blogs.imf.org/2017/05/13/every-woman-counts-gender-budgeting-in-g7-countries/\#more-19724. Acesso em: 10 de março de 2021 .

LEWICKI, Roy J.SAUNDERS, David M. BARRY, Bruce. Fundamentos de Negociação. 5a Ed. Porto Alegre: AMGH, 2014.

MANNKIW, Gregory N. Princípios de Macroeconomia. 6a Ed. São Paulo: Cengage Learning, 2013.

MONTEIRO, José-Antonio. The Evolution of gender-related provisions in regional trade agréments. Economic Research and Statistics Division (ERSD). Geneva: World Trade Organization,2021. https://www.wto.org/english/res_e/reser_e/ersd202108_e.pdf. Acesso em: 10 de março de 2021.

NELSON, Julie. Feminism and Economics. Journal of Economic Perspectives, Nashville,v. 9, n. 2, p. $131148,1995$.

OLIVEIRA, Osmany Porto; SARAIVA, Camila; SAKAI, Roberta. Difusão de Políticas e Cooperação para o Desenvolvimento: elementos norteadores para a implementação de projetos de transferência de políticas públicas por meio da cooperação internacional. São José do Rio Preto, SP: Balão Editorial, 2020.

ORGANISATION FOR ECONOMIC CO-OPERATION AND DEVELOPMENT - OECD. Recommendation of the Council on Gender Equality in Education, Employment and Entrepreneurship. Paris: OECD, 2013. Disponível em: https://read.oecdilibrary-org/employment/2013-oecd-recommendation-of-the-council-on-gender-equality-in-education-employment-andentrepreneurship_9789264279391-en\#page1. Acesso em :10 de abril de 2021.

ORGANISATION FOR ECONOMIC CO-OPERATION AND DEVELOPMENT - OECD. Women's Economic Empowerment. Paris: OECD: 2021. Disponível em:<https://www.oecd.org/development/womens-economic-empowerment.htm>. Acesso em: 10 de março de 2021.

OROZCO, Amaia Pérez. Economía del Género y Economía Feminista: conciliación o ruptura? Revista Venezoelana de Estudios de La Mujer, Caracas, v.10, n. 24, p.43-64,2005. Disponível em: https://dialnet.unirioja.es/servlet/articulo?codigo=5855457. Acesso em: 20 de abril de 2021. 
OROZCO, Amaia Pérez. Perspectivas feministas en torno a la Economía: el caso de los cuidados. Madrid: Consejo Económico y Social, Colección Estudios, 2006. Disponível em: https://porunavidavivible.files.wordpress.com/2012/09/perez - orosco.pdf. Acesso em: 07 de julho de 2021.

PETERSON, Spike V. A Critical Rewriting of Global Political Economy: Integrating reproductive, productive and virtual economies. Londres: Routledge, 2003.

PETERSON, Spike V. How (the Meaning of) Gender in Political Economy. New Political Economy. Londres, v. 10, n. 4, p. 459-521, 2005.

SARDENBERG, Cecília M.B. Liberal vs Liberating Empowerment: A Latin American Feminist Perspective on Conceptualizing Women `s Empowerment. IDS-Institute of Development Studies, Brighton, v.39, n. 6, p.18-27, 2008. Disponível em: https://onlinelibrary.wiley.com/doi/abs/10.1111/j.1759-5436.2008.tb00507.x. Acesso em 20 de abril de 2021

TICKNER, J. Ann. Gendering World Politics. Nova York: Columbia University Press, 2001.

THE WORLD BANK GROUP. WORLD TRADE ORGANIZATION - WTO. Women and Trade: the role of trade in promoting gender equality. Washington: The World Bank, World Trade Organization, 2020. Disponível em https://www.wto.org/english/res_e/publications_e/women_trade_pub2807_e.htm .Acesso em:20 de abril de 2021.

TRUE, Jacqui. The Political Economy of violence against women. Oxford: Oxford University Press, 2012.

UNITED NATIONS - UN. The Convention on the Elimination of All Forms of Discrimination against Women (CEDAW). 1979. Disponível em: https://www.un.org/womenwatch/daw/cedaw/. Acesso em: 15 de abril de 2021.

UNITED NATIONS - UN. The United Nations Fourth World Conference on Women. 1995. Disponível em: https://www.un.org/womenwatch/daw/beijing/platform/plat1.htm\#statement. Acesso em: 10 de março de 2021.

UNITED NATIONS - UN. General Assembly. Draft resolution referred to the United Nations summit for the adoption of the post2015 development agenda by the General Assembly at its sixty-ninth session. Transforming our world: the 2030 Agenda for Sustainable Development. 2015. Disponível em: https://undocs.org/A/70/L.1. Acesso em: 10 de março de 2021.

UNITED NATIONS INTERREGIONAL CRIME AND JUSTICE RESEARCH INSTITUTE - UNICRI. Women empowerment and countering gender-based violence to support development. 2021. Disponível em: http:/www.unicri.us/topics/violence_women/. Acesso em: 29 de março de 2021.

UN WOMEN. Facts and Figures: Economic Empowerment. 2018. Disponível em: https://www.unwomen.org/en/what-wedo/economic-empowerment/facts-and-figures. Acesso em:10 de março de 2021

UN WOMEN. Families in a changing World. 2019. Disponível em: https://www.onumulheres.org.br/wpcontent/uploads/2019/06/Progress-of-the-worlds-women-2019-2020-en.pdf. Acesso em: 10 de março de 2021.

WORLD BANK. World Bank Group gender strategy (FY16-23): gender equality, poverty reduction and inclusive growth. 2015. Disponível em https://documents.worldbank.org/en/publication/documents - reports/documentdetail/820851467992505410/world bank-group-gender-strategy-fy16-23-gender-equality-poverty-reduction-and-inclusive-growth. Acesso em: 15 de março de 2021.

WORLD BANK. The World Bank In Gender. 2020. Disponível em: https://www.worldbank.org/en/topic/gender/overview\#: :text=The\%20World\%20Bank\%20Group's\%20Gender,gender\%20equality \%20and\%20 economic\%20development. Acesso em: 15 de março de 2021.

WORLD ECONOMIC FORUM - WEF. Agenda in focus: women and work. 2021. Disponível em: https://www.weforum.org/focus/women-and-work . Acesso em 15 de março de 2021.

WORLD ECONOMIC FORUM - WEF. Global Gender Gap Report 2021. Cologny/Geneva: World Economic Forum. Disponível em: http://www3.weforum.org/docs/WEF_GGGR_2021.pdf. Acesso em: 01 de abril de 2021.

WORLD TRADE ORGANIZATION - WTO. International Women's Day. 2011. Disponível em: https://www.wto.org/english/forums_e/women_day_e/women_day_e.htm. Acesso em:15 de março de 2021.

WORLD TRADE ORGANIZATION - WTO. Eleventh WTO Ministerial Conference. 2017a. Disponível em: https://www.wto.org/english/thewto_e/minist_e/mc11_e/mc11_e.htm . Acessoem: 15 de março de 2021.

WORLD TRADE ORGANIZATION - WTO. Joint Declaration on Trade and Women's Economic Empowerment on the Occasion of the WTO Ministerial Conference in Buenos Aires in December 2017. 2017b. Disponível em: https://www.wto.org/english/thewto_e/minist_e/mc11_e/genderdeclarationmc11_e.pdf . Acesso em: 15 de março de 2021.

WORLD TRADE ORGANIZATION - WTO. Interim report following the Buenos Aires Joint Declaration on Trade and Women's $\begin{array}{lllll}\text { Economic } & \text { Empowerment. } & \text { WT/L/1095/Rev.1. } & 2020 . & \text { Disponível }\end{array}$ https://www.wto.org/english/tratop_e/womenandtrade_e/iwg_trade_gender_e.htm. Acesso em: 12 de abril de 2021.

WORLD TRADE ORGANIZATION - WTO. Women and trade. 2021. Disponível em: https://www.wto.org/english/tratop_e/womenandtrade_e/womenandtrade_e.htm. Acesso em: 12 de abril de 2021. 
WORLD TRADE ORGANIZATION - WTO. Informal Working Group on Trade and Gender. 2021. Disponível em: https://www.wto.org/english/tratop_e/womenandtrade_e/iwg_trade_gender_e.htm. Acesso em: 12 de abril de 2021.

WORLD TRADE ORGANIZATION - WTO. Final Work Plan for Implementing Activities under the Informal Working Group on

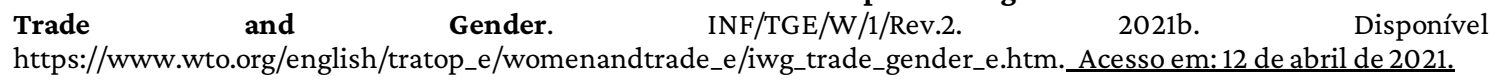

WORLD TRADE ORGANIZATION (WTO). Women Pioneers at WTO 2021c. Disponível em: https://www.wto.org/english/thewto_e/25y_e/25yportrait_e.htm. Acesso em: 12 de abril de 2021.

Funções de colaboração exercidas 